\title{
Medidas de democracia em surveys
}

\begin{tabular}{c}
\hline Richard Rose \\
Centre for the Study of Public Policy \\
University of Strathclyde \\
\hline \hline
\end{tabular}

\section{Resumo}

Este artigo examina como as questões dos surveys sobre democracia são estruturadas de modos diferentes, dependendo do emprego de uma definição idealista ou realista e da presença ou não de comparações com regimes alternativos. Começo mostrando medidas de democracia em países pós. comunistas que perguntam às pessoas se estão satisfeitas ou não com a democracia e pedem que a comparem com um padrão ideal. As seções posteriores apresentam os resultados de questões realistas do New Democracies Barometer, que pedem às pessoas para avaliar regimes do passado, do presente e do futuro - e alternativas não-democráticas historicamente familiares.

Palavras-chave: democracia, perguntas de survey, cultura política, regimes pós-comunistas

\begin{abstract}
This paper examines how survey questions about democracy are framed in different ways, depending upon whether an idealist or realist definition is employed, and whether or not comparisons are made with alternative regimes. It starts by reporting measures of democracy in post-Communist countries that ask people whether they are satisfied with democracy and to compare it with an ideal standard. Subsequent sections set out the results of realist questions from the New Democracies Barometer, which ask people to evaluate regimes past, present and future-and historically familiar undemocratic regimes that people have known.
\end{abstract}

Key words: democracy, political culture, survey questions, post-Communist regimes 
Em uma sociedade em transformação, permanece aberta a questão de se as pessoas preferem um regime democrático ou não-democrático. O colapso das forças do velho regime força as elites políticas a criar novas instituições políticas. Mas um novo regime só pode se tornar uma democracia estabelecida se suas instituições receberem o apoio de uma grande maioria da população. As teorias institucionais da democracia cometem um erro fundamental se partirem do suposto de que a reação dos indivíduos às novas instituições é determinada por características específicas do projeto institucional, e o risco de erro aumenta nas sociedades pós-comunistas, onde o mercado e as instituições democráticas estão sendo introduzidos ao mesmo tempo. Essas instituições não funcionarão como pretendido se aqueles que elas devem representar negam seu apoio.

A hipótese de Churchill enfatiza a competição entre os regimes. Numa democracia nova, as atividades das elites políticas e o funcionamento de novas instituições políticas são influências significativas sobre a democratização, mas qualquer análise da transformação está incompleta sem provas empíricas da resposta popular. O que fazem os indivíduos quando confrontados com uma escolha entre apoiar um regime novo, com todas as falhas que instituições não testadas podem ter, ou preferir alternativas não-democráticas? Para responder a essa questão é necessário ter dados obtidos por surveys que façam as perguntas apropriadas à situação.

Não é realista esperar que questões emprestadas de pesquisas de opinião pública em democracias estabelecidas sejam suficientes para entender o que está acontecendo em sociedades em transformação. Numa democracia estabelecida, não há escolha entre regimes. Por definição, as perguntas sobre a avaliação das instituições de um regime democrático não têm significação política, pois a legitimidade do regime não está em questão. É evidente que se pode pedir aos cidadãos que avaliem como as instituições estão funcionando e quão satisfeitos estão com o desempenho dos líderes ou dos partidos políticos. Se as pessoas estão insatisfeitas, as eleições proporcionam uma pronta alternativa: "pôr na rua os patifes", ao mesmo tempo em que o regime permanece intacto. Questões desse tipo são inadequadas para medir a amplitude das opções com que a população se defronta num sistema político em que há competição entre regimes. Tratar as respostas negativas a tais perguntas como se elas ameaçassem derrubar a Constituição americana ou o sistema parlamentarista inglês é um convite à confusão, devido à utilização de medidas não apropriadas (ver Weatherford, 1987, 5ss; 1992, 151).

Nos países pós-comunistas, é realista fazer perguntas sobre diferentes regimes, pois todos os adultos viveram sob pelo menos dois deles, um que aspira a ser democrático e outro com aspirações totalitárias, e as pessoas mais velhas passaram por até quatro regimes não-democráticos diferentes. A questão é: que 
tipos de perguntas devem ser usados? As definições realistas e idealistas de democracia implicam diferentes tipos de questões. As abordagens idealistas enfatizam os valores e objetivos dos teóricos democráticos e tendem a ignorar as instituições realmente existentes. Uma segunda estratégia é pedir às pessoas para comparar o funcionamento do regime atual com um padrão ideal. Essa abordagem é consistente com a distinção de Dahl entre democracia e poliarquia (1971); é também apropriada para uma democracia estabelecida, pois as pessoas não têm a experiência de um regime não-democrático. Para testar a hipótese de Churchill, deve-se pedir às pessoas para comparar alternativas reais, e isso tem sentido fazer em democracias novas.

\section{Perguntando sobre ideais}

Para explicar o apoio à democracia, precisamos identificar um grupo da população que seja a favor dela e um grupo que seja contrário. Porém, embora exista um acordo substancial entre os cientistas políticos contemporâneos no sentido de endossar a poliarquia de Robert Dahl como uma definição apropriada de democracia, eles não concordam sobre a melhor maneira de medir o compromisso dos cidadãos com os ideais democráticos.

Uma vez que a democracia é um símbolo, ela é um verdadeiro "borrão de tinta" que os indivíduos podem interpretar como quiserem; portanto, formular a pergunta direta - Você é a favor ou contra a democracia? - é impróprio. Se a democracia for associada à criminalidade, que cresceu dramaticamente nos países pós-comunistas, é provável que as avaliações sejam negativas. Mas se for associada ao aumento da liberdade individual, as avaliações serão provavelmente positivas.

Os múltiplos significados do símbolo da democracia podem ser investigados com a formulação de uma questão aberta que estimule as pessoas a dizer o que pensam dela. Isso foi feito num survey sobre Cultura Política realizado em doze países e várias línguas da Europa central e oriental por Laszlo Bruszt e Janos Simon, de Budapeste, em 1990-92, que perguntava: O quê a democracia significa para você? Embora os entrevistados tivessem passado quase toda a vida em regimes não-democráticos, a palavra tinha algum sentido para uma média de $76 \%$ dos respondentes. Quando se pedia às mesmas pessoas para dizer o que os termos "esquerda" e "direita" significavam, a proporção de "não sei" foi quase duas vezes maior (Simon, 1996, tabela 5).

Em qualquer língua, a democracia provoca uma variedade de respostas - e a maioria delas é positiva (Simon, 1996, 16 ss). A liberdade é a característica geralmente mencionada pela maioria dos respondentes. Embora seja de importância política fundamental, a liberdade não é em si mesma o mesmo que "governo pelo povo". Ela é uma condição necessária do governo democrático, mas 
não suficiente. A participação, os benefícios do bem-estar social e os direitos legaisinstitucionais são mencionados como significando democracia por pelo menos dez por cento dos respondentes.

O significado polivalente de democracia é confirmado por um estudo similar feito na Rússia e na Ucrânia por uma equipe de pesquisa da Universidade de lowa (Miller, Hesli e Reisinger, 1997, em especial tabela 3). Seus surveys nacionais e de elite perguntaram: O quê a democracia significa pessoalmente para você? Entre os russos, 25\% responderam "não sei" e entre os ucranianos, 29\%. Em contraste, menos de dez por cento das amostras de elites não tinham opinião. As respostas mais freqüentes interpretavam a democracia como significando liberdade, o império da lei e todos agindo de modo responsável e decente uns em relação aos outros, o que são condições necessárias da democracia, mas não suficientes para alcançar o governo pelo povo. Na Rússia e na Ucrânia, uma pessoa em cada sete via a democracia como símbolo negativo.

2. Uma vez que as pessoas comuns podem imputar uma multiplicidade de significados à democracia, faz sentido combinar as respostas a uma multiplicidade de perguntas numa única escala de democracia. Essa combinação tem a vantagem técnica de aumentar a confiabilidade do indicador, pois os erros aleatórios no registro de respostas a uma única questão têm sua significação reduzida à medida que o número de questões na escala aumenta.

Um exemplo de uma medida de democracia de múltiplos atributos encontrase na análise de surveys realizados na Rússia e Ucrânia por James L. Gibson (1994, 12 ss, em especial tabela B.1). O questionário inclui 19 itens diferentes relacionados à democracia por filósofos políticos e apresentados voluntariamente em resposta a questões abertas. Na Rússia, a questão média provocou $26 \%$ de "não sei" e na Ucrânia, 28\%. Não obstante, num processo de dois estágios, o grande número de respostas pode ser reduzido a uma única escala. Primeiro, as perguntas foram agrupadas em sete tópicos diferentes: liberdade, eleições competitivas, sistema multipartidário, mídia pluralista, consciência dos direitos, visões de discordância e oposição e tolerância política. Cada grupo passou por análise fatorial, produzindo-se sete escalas. Em segundo lugar, as escalas foram então combinadas por análise fatorial numa única medida de apoio às instituições e aos processos democráticos (ibid., 1994: nota 27; ver também Gibson, Duch \& Tedin, 1992). Embora estatisticamente válida, a confiança em valores abstratos significou que a escala não se referia a nenhum regime democrático existente.

3. Uma abordagem alternativa é considerar a democracia como um elemento numa matriz multidimensional de valores políticos. Por exemplo, no survey de doze países de Bruszt e Simon, as respostas a onze questões sobre atributos da democracia foram reduzidas, por análise estatística, a três dimensões: instituições políticas, preocupações socioeconômicas e direitos liberais ou individuais (Simon, 
1996, 5 ss). Ao mesmo tempo em que cada grupo é relevante para a análise dos valores políticos, os indivíduos diferiam em relação aos valores que associavam à democracia. Algumas pessoas achavam que a democracia tinha de ver principalmente com benefícios socioeconômicos, enquanto outras achavam que ela se relacionava com direitos individuais ou instituições políticas. Nessas circunstâncias, os partidos políticos podem competir oferecendo definições muito diferentes de democracia: um partido socialista pode enfatizar os benefícios sociais e econômicos, um partido liberal, os direitos individuais, e um conservador, a autoridade das instituições (cf. Barnes, 1967).

A introdução simultânea do livre mercado e de instituições políticas livres nos países pós-comunistas estimula a ligação entre o apoio às mudanças políticas e o apoio às mudanças econômicas. Em surveys realizados na Hungria, Polônia, Romênia e Bulgária, McIntosh, Mclver e Abele (1994) construíram medidas separadas de apoio aos princípios democráticos liberais e à economia de mercado, e depois examinaram em que medida as pessoas ligam os dois valores, ou são "liberais" em política, mas "socialistas" em economia. Eles encontraram um apoio quase universal para elementos de democracia política, mas desacordo substancial sobre os valores econômicos. Além disso, as atitudes em relação à economia de mercado não estão associadas ao alto nível de apoio à democracia. Esses resultados refutam o pressuposto dos economistas liberais de que os apoios ao mercado e à democracia andam juntos, e o dos comunistas de que as instituições socialistas sem mercado constituem uma democracia (cf. McIntosh \& Abele, 1994).

4. Os surveys de cultura política avaliam se os cidadãos são democratas, bem como interrogam sobre as instituições políticas. A lógica é a seguinte: se a grande maioria da população segue valores democráticos, o país deveria ter uma forma democrática de governo. O pressuposto subjacente de que o governo é "o que o povo quer" justifica-se com mais facilidade com base na história americana ou inglesa do que na história anterior dos países pós-comunistas.

The Civic Culture, de Gabriel Almond e Sidney Verba (1963), foi obra pioneira na coleta de dados de survey para caracterizar as culturas políticas em três países considerados então em processo de democratização - Alemanha, Itália e México - e em duas democracias estabelecidas, Estados Unidos e Grã-Bretanha. O questionário concentrou-se muito mais no comportamento dos indivíduos do que no modo como os respondentes avaliavam suas experiências de vida sob diferentes regimes, democráticos ou não-democráticos. Encontraram-se diferenças substanciais tanto no interior de cada país como entre países, na medida em que as pessoas refletiam valores e comportamentos cívicos, ou eram mais ou menos passivas na aceitação da autoridade (consistente com regimes não-democráticos). Muitos indivíduos combinavam atitudes contrastantes, acreditando, por exemplo, que poderiam influenciar o governo se quisessem, mas, na verdade, não tentavam 
fazer isso (ibid. 474). Os autores concluíram que a democracia florescia onde havia uma "cultura política mista" de ativistas cívicos, sujeitos passivos e algumas pessoas sem contato com a política.

O conceito de cultura política foi alargado para incluir uma ampla variedade de relações sociais consideradas normalmente não-políticas. Harry Eckstein (1966, 225-288) sustentou que uma cultura política democrática é mais segura quando há uma "congruência" de valores com respeito à autoridade em diferentes setores da sociedade, como a família, a escola e o local de trabalho, além do governo (ver também Dahl, 1985). Robert Putnam (1993) afirmou que a participação em grupos sociais informais, tais como clubes esportivos e corais, estimula a confiança e a cooperação com os outros. Essas atitudes "transbordam" para a participação em instituições políticas cívicas e representativas, tais como grupos dedicados a uma única questão, e "se disseminam para cima", influenciando o governo e fazendo assim funcionar a democracia.

Muitos estudiosos das sociedades comunistas, em especial da Rússia soviética, ficaram intrigados com o estado mental das pessoas governadas por um regime totalitário ou pós-totalitário. Em que medida os valores pré-comunistas ainda eram importantes, fossem congruentes com o regime soviético, como a obediência à autoridade russa, ou incongruentes, como o catolicismo na Polônia? Em que medida o Partido Comunista conseguiu refazer os valores e as crenças de seus súditos e obter uma ampla base de apoio popular? (cf. Tucker, 1971; Jowitt, 1974; White, 1979; Brown, 1984; Welch, 1987). Com freqüência, a resposta foi que os regimes comunistas tinham conseguido "refazer" os valores políticos de seus povos. Umas poucas interpretações afirmavam que havia uma cultura dualista, em que os indivíduos exibiam um conjunto de valores para consumo público e outro em privado. Os estudiosos enfatizavam cada vez mais o potencial autônomo para mudanças à medida que a industrialização e a maior instrução encorajavam o surgimento de valores mais "modernos" ou até "democráticos". Os argumentos eram sustentados por inferências tiradas do comportamento ou da ideologia oficial promulgada por instituições comunistas. Não havia praticamente nenhuma pesquisa de amostragem que fornecesse indícios do que as pessoas pensavam.

A cultura política é muito útil para explicar "as opções rotineiras, geralmente não examinadas, da maioria das pessoas na maior parte do tempo" (Barnes, 1994, 53). No entanto, o colapso de um regime comunista e sua substituição por outro foi tudo, menos rotina: ele forçou os indivíduos a mudar o comportamento. Mas essas mudanças de comportamento, tais como votar em eleições competitivas, significaram a adoção de atitudes democráticas? Na medida em que os valores correntes pareciam consistentes com a democracia, isso significava que eles existiam antes do colapso do comunismo?

A maioria dos surveys acadêmicos realizados nos países pós-comunistas foi 
feita conscientemente dentro do marco da cultura política, perguntando sobre ideais democráticos e se os indivíduos tinham ou não valores democráticos (para uma resenha, ver Fleron, 1996). O maior número de surveys foi realizada na Rússia, país para o qual escritos anteriores sugeriam que as atitudes democráticas seriam mais fracas. Apesar disso, Jeffrey Hahn (1991), um antigo estudioso da cultura soviética, concluiu que em muitos indicadores convencionais de cultura política, os russos eram com freqüência tão positivos em relação a valores e crenças democráticas quanto os americanos que responderam a perguntas semelhantes em estudos eleitorais da Universidade de Michigan. Esses resultados aparecem com a mesma freqüência em outros surveys (ver por ex., Miller et al., 1994; Finifter e Mickiewicz, 1992).

As pesquisas pós-soviéticas destruíram a crença de que quase todo mundo que vive na Europa central e oriental, seja democrata ou comissário, pensa da mesma forma. Todos os surveys enfatizam que no interior de uma sociedade, há diferenças no modo como as pessoas pensam. Ainda que uma grande ou pequena maioria, ou pelo menos uma pluralidade, endosse os ideais democráticos, há uma pequena ou grande minoria que não o faz. Assim, a interpretação é problemática. Se uma pequena maioria a favor de valores democráticos é uma prova dificilmente conclusiva de uma cultura democrática, é ainda menos realista exigir cem por cento de apoio para o estabelecimento de uma democracia. Por exemplo: os Estados Unidos têm um regime democrático estabelecido ainda que, durante gerações, as pesquisas mostrem que alguns cidadãos não são democratas ideais (ver Adorno et al., 1950; Sniderman, 1993, 227 ss.).

O endosso aos ideais democráticos não é suficiente para estabelecer um regime democrático, pois um regime é antes de tudo uma questão de instituições políticas. Enquanto a abordagem institucionalista tende a ignorar o que as pessoas comuns pensam, a perspectiva da cultura política tende a ignorar as instituições. Inferir o caráter das instituições políticas apenas de dados de surveys é cometer o que Scheuch (1966) chamou de falácia "individualista", isto é, supor que as macroinstituições da sociedade não passam de reflexo do que os indivíduos (ou uma determinada porcentagem da população) querem. Essa confusão é freqüente. Por exemplo: na interpretação de Gibson e Duch $(1993,253)$, o survey que fizeram na Rússia soviética de 1990 mostra que o povo tem alta consciência de seus direitos políticos. Ao comparar as respostas dos russos com as respostas às mesmas perguntas em outros países, eles concluem: "Isso coloca a União Soviética entre as sociedades mais conscientes de seus direitos quando comparada com a Europa ocidental". Trata-se de uma conclusão que ignora que essa consciência na Rússia se devia-se ao fato do regime negar tais direitos. É necessário estabelecer a conexão entre atitudes idealistas com regimes políticos para se concentrar em questões que tenham fundamento institucional (ver Weatherford, 1992, 149). 


\section{Ideais na prática}

Para estabelecer a ligação do mundo ideal com as instituições políticas existentes, as pesquisas podem pedir às pessoas para comparar o ideal democrático com a prática real da democracia em seu país. Isso avança meio caminho na direção de cumprir as condições necessárias para testar a hipótese de Churchill, pois há uma medida do que as pessoas experimentaram. Mas não vai até o fim, pois não se pede às pessoas para avaliar regimes alternativos que foram experimentados. Nem se pode fazer isso numa democracia estabelecida, pois por definição, trata-se do único regime que os cidadãos experimentaram.

1. Numa democracia estabelecida, pedir às pessoas para avaliar a forma ideal de democracia em comparação com a prática atual de governo é simples e teoricamente útil, refletindo a distinção de Dahl entre democracia e poliarquia e medindo a distância entre o que as pessoas julgam mais desejável e o sistema existente. O Eurobarômetro multinacional pergunta: Em geral, você está muito satisfeito, razoavelmente satisfeito, não muito satisfeito ou nada satisfeito com a maneira como a democracia está se desenvolvendo em seu país? Os resultados são usados com freqüência pelos cientistas sociais porque o Eurobarômetro é patrocinado pela Comissão Européia. Uma vez que a pergunta foi feita em quinze países durante duas décadas e é feita agora na Europa central e oriental e na antiga União Soviética, é possível fazer comparações de tendências por um período de duas décadas (ver por ex. Fuchs et al., 1995).

No interior da União Européia, os cidadãos discordam sobre o bom ou mau funcionamento da democracia em seu país. Numa democracia estabelecida, somente três por cento respondem que não sabem, mas a pessoa média está insatisfeita com a democracia. Em média, 53\% dos cidadãos das democracias estabelecidas da União Européia dizem estar razoavelmente ou muito satisfeitos, enquanto que $47 \%$ estão, em maior ou menor grau, insatisfeitos (Figura 1). As diferenças entre as nações são substanciais: somente $19 \%$ dos italianos se disseram satisfeitos com a democracia, em contraste com 79\% dos dinamarqueses.

Em nove países pós-comunistas há uma divisão de opinião semelhante sobre o funcionamento da democracia: somente $29 \%$ afirmam que estão muito ou razoavelmente satisfeitos. Porém, há diferenças substanciais entre países. Na República Tcheca, a metade diz estar satisfeita, e entre os poloneses, $42 \%$ afirmam essa satisfação. Em contraste, na Belarus somente $16 \%$ dizem estar satisfeitos com seu novo regime, dificilmente um modelo de democracia, e na Ucrânia, apenas 17\%. A quantidade limitada de satisfação com a democracia é uma característica recorrente dos surveys realizados na Europa pós-comunista, o mesmo ocorrendo com o padrão de diferenças entre nações em satisfação e insatisfação (cf. Berglund e Aarebrot, 1997, 123 ss.; Toka, 1995, 354). 
Os cidadãos de democracias estabelecidas deveriam estar mais satisfeitos com sua forma de governo do que os de democracias nascentes. Portanto, é digno de nota que as médias exibidas na Figura 1 não possam ser projetadas para todos os regimes. Em sete dos nove países da Europa central e oriental os cidadãos mostram um nível mais alto de satisfação com a democracia do que na Itália, e em quatro países - República Tcheca, Polônia, Eslovênia e Romênia - mais pessoas revelam satisfação com a democracia do que na Grécia ou na Espanha. Além disso, a grande maioria dos cidadãos evita os extremos. Numa escala de quatro pontos com duas alternativas moderadas e duas extremas, somente sete por cento dos respondentes da União Européia dizem que estão muito satisfeitos com o funcionamento da democracia em seu país. De modo similar, somente dois por cento dos europeus orientais e centrais afirmam estar muito satisfeitos. De maneira complementar, somente $14 \%$ dos cidadãos da União Européia e $20 \%$ dos da Europa central e oriental dizem estar muito insatisfeitos. Na Europa pós-comunista, a pessoa média não está muito satisfeita com o modo como se desenvolve a democracia. Essa visão é consistente com a defesa de uma reforma da democracia para que ela funcione melhor, ou com sua rejeição em favor de um regime nãodemocrático.

\section{FIGURA 1}

Grau de satisfação com a democracia: comparação entre Europa ocidental e oriental

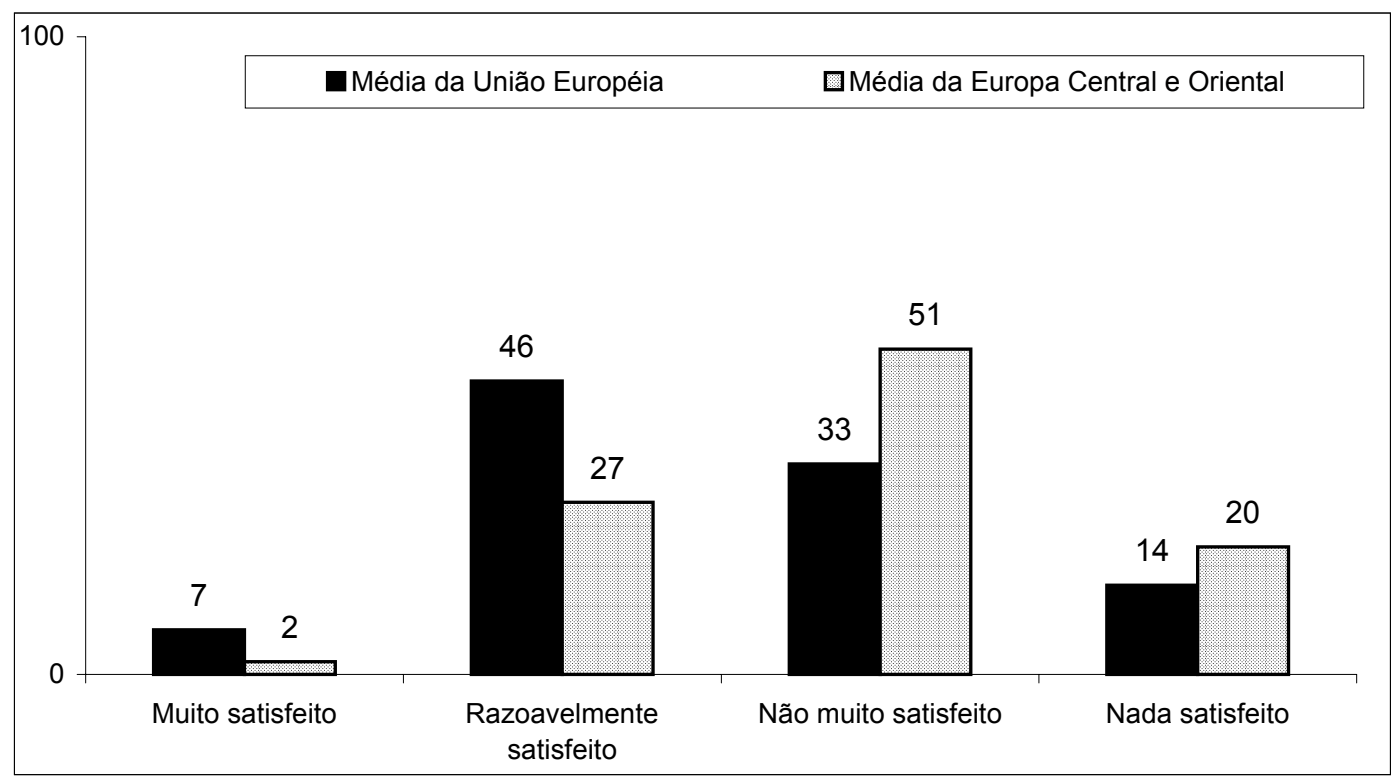

Fonte: Para nove países do New Democracies Barometer, Central and Eastern Eurobarometer (Bruxelas: European Commission Report n. ${ }^{\circ}$ 4, 1994), Figura anexa 7. Pesquisa de campo em novembro-dezembro de 1993. Número total de entrevistas: 9.165. Para os doze Estados-membros da União Européia, com pesquisa de campo em abril-maio de 1994, ver Eurobarometer (Bruxelas, European Commission n. ${ }^{\circ}$ 41, 1994), A 11, tabela 2. Número total de entrevistas: 13.029. 
A questão sobre satisfação com a democracia está formulada em termos genéricos, de tal forma que pode ser usada em qualquer país, mas a falta de uma âncora institucional é uma debilidade, pois respostas idênticas a esta pergunta não têm o mesmo significado em contextos institucionais diferentes. Uma pessoa que declara estar insatisfeita com o desenvolvimento da democracia na Belarus ou Ucrânia está avaliando um regime muito diferente do que uma pessoa que diz a mesma coisa na Dinamarca ou na Holanda. As respostas são totalmente subjetivas; elas não levam em conta a diferença entre a insatisfação com um regime que se situa no topo da classificação da escala da Freedom House e aquela que diz respeito a um regime que é classificado como "parcialmente livre". A satisfação com a democracia não pode ser utilizada para testar a hipótese de Churchill, pois não há maneira de saber se uma pessoa não muito satisfeita com o modo como se desenvolve a democracia não seria mais negativa ainda com respeito a um regime comunista.

O hiato entre o ideal e a prática da democracia foi medido por Evans e Whitefield (1995, 489 ss.) num survey realizado em 1993 em oito países póscomunistas: Bulgária, Estônia, Hungria, Lituânia, Polônia, Romênia, Rússia e Ucrânia. Primeiro perguntou-se: Como você se sente em relação ao propósito de introduzir a democracia neste país, com partidos que competem pelo governo? Um total de $55 \%$ foi positivo com respeito à idéia de democracia, $29 \%$ disseram que não sabiam e o menor grupo, $16 \%$, foi negativo. As respostas positivas superaram as negativas por uma margem de mais de três para uma. Quando se perguntou às pessoas - Como você avaliaria a prática real da democracia até agora neste país? - o padrão se inverteu. O maior grupo, 47\%, foi negativo, os que responderam "não sei" totalizaram $31 \%$ e somente $22 \%$ foram positivos. Em todos os países, os que estavam a favor dos objetivos democráticos superaram de longe os que eram contra, e os que se manifestaram negativamente sobre a prática da democracia superaram os que tinham uma visão positiva. A pessoa média de um país póscomunista mostrava aprovação do objetivo da democracia, mas desaprovava a prática de governo em seu sistema recentemente democratizado.

As teorias da frustração e do comportamento político supõem que quanto maior a distância entre o ideal democrático e a prática democrática, maior o risco de frustração que conduza a uma ação agressiva que desestabilize uma nova democracia (Gurr, 1970). Na pesquisa de Evans e Whitefield, cerca de um terço dos respondentes estavam frustrados, sendo a favor da democracia em teoria, mas insatisfeitos com sua prática; um quinto estava satisfeito com ambas; um sexto era contra a democracia tanto na teoria como na prática; e cerca de um terço manifestou apatia. Tal como a maioria dos cientistas políticos que usam surveys, os autores não enfocaram macro-instituições, mas as atitudes dos indivíduos por si mesmos, e concluíram que quanto mais positiva é a avaliação da prática da 
democracia, maior o compromisso normativo dos indivíduos com a democracia como um ideal (Ibid., tabela 6). A quantidade de frustração que pode ser tolerada num sistema é deixada em aberto. A omissão de questões sobre alternativas à democracia torna impossível testar a hipótese de Churchill, uma vez que a distância entre a democracia na teoria e na prática poderia ser preferida à distância entre a prática de um regime não-democrático e as realizações correntes de uma nova democracia.

2. O hiato entre formas ideais e reais de democracia não surpreende, mas a questão crítica é: qual é o significado dessa distância? Ela implica que aqueles que percebem uma diferença vão preferir fechar a brecha com uma reforma ou revolução? Essa questão é tratada em um estudo das novas democracias em Portugal, Espanha, Itália e Grécia, que pediu às pessoas para escolher entre três alternativas: nossa democracia funciona bem; nossa democracia tem muitos defeitos, mas funciona; ela está ficando pior e não vai funcionar mesmo (Tabela 1).

Em 1985, quando os habitantes de democracias mediterrâneas recentemente estabelecidas foram pesquisados, a maioria via muitos defeitos na democracia, mas acreditava que ela funcionava. Menos de uma em cinco achava que o regime estava ficando pior e jamais funcionaria. Isso implica uma demanda por reformar a democracia com a remoção de seus defeitos, em vez de rejeitar o regime e tentar outra forma de governo. Os surveys da Comissão Européia (1989, tabela B3) também concluem que quando as pessoas avaliam sua sociedade, uma grande maioria é invariavelmente a favor da reforma, em vez de dar um endosso geral ao status quo ou pedir uma mudança revolucionária.

\section{TABELA 1}

\section{Atitudes em relação à democracia existente}

\begin{tabular}{|l|r|r|r|r|c|}
\cline { 2 - 7 } \multicolumn{1}{c|}{} & $\begin{array}{c}\text { Portugal } \\
\%\end{array}$ & $\begin{array}{c}\text { Espanha } \\
\%\end{array}$ & $\begin{array}{c}\text { Itália } \\
\%\end{array}$ & $\begin{array}{c}\text { Grécia } \\
\%\end{array}$ & $\begin{array}{c}\text { Média } \\
\%\end{array}$ \\
\hline Avaliação do regime atual & 5 & 8 & 4 & 35 & 13 \\
\hline Nossa democracia funciona bem & 63 & 60 & 61 & 45 & 57 \\
\hline Tem muitos defeitos, mas funciona & 11 & 20 & 28 & 14 & 18 \\
\hline Está ficando pior e não vai funcionar & 21 & 11 & 6 & 4 & 11 \\
\hline Não sei
\end{tabular}

3. A avaliação contingente da democracia pressupõe que esse regime não é ideal para todos os objetivos: pode funcionar bem em algumas circunstâncias, mas em outras, um regime não-democrático pode ser melhor. Essa visão é consistente com a crença de que, embora seja desejável, a democracia não é igualmente apropriada a todas as circunstâncias. Quando a pergunta é feita nos países da União Européia, mais de três quartos dos entrevistados dão um apoio absoluto à 
democracia como preferível a qualquer outro tipo de regime (Tabela 2). Dos restantes, um oitavo não tem opinião ou acha que a forma de governo não faz diferença. Menos de um em dez acreditam que, em algumas circunstâncias, um regime não-democrático é melhor. O compromisso com a democracia é tão forte nos países mediterrâneos que tiveram a mais recente exposição a um governo nãodemocrático quanto nas democracias européias bem estabelecidas, enfatizando que as pessoas que experimentaram um regime não-democrático conhecem bem suas deficiências. Na América Latina, a mesma pergunta revelou uma maioria que dá um apoio sem qualificações à democracia em nove diferentes países, inclusive muitos que tiveram experiências recentes de regimes autoritários ou ditatoriais.

\section{TABELA 2}

Compromisso absoluto versus contingente com a democracia

Pergunta - Com qual das seguintes afirmações você concorda mais?

a) A democracia é preferível a qualquer outro tipo de governo.

b) Em certas situações, um governo autoritário pode ser preferível a um democrático.

c) Para pessoas como eu, não importa se temos um governo democrático ou nãodemocrático.

\begin{tabular}{|l|c|c|c|c|}
\cline { 2 - 5 } \multicolumn{1}{c|}{} & $\begin{array}{c}\text { Democracia } \\
\%\end{array}$ & $\begin{array}{c}\text { Autoritário } \\
\%\end{array}$ & $\begin{array}{c}\text { Não importa } \\
\%\end{array}$ & $\begin{array}{c}\text { Não sabe } \\
\%\end{array}$ \\
\hline Grécia & 90 & 4 & 3 & 2 \\
\hline Portugal & 83 & 9 & 4 & 4 \\
\hline Espanha & 78 & 9 & 7 & 6 \\
\hline Itália & 73 & 14 & 6 & 7 \\
\hline Média de 12 países da UE & 78 & 9 & 8 & 5 \\
\hline América Latina: média de 9 países & 61 & 18 & 16 & 5 \\
\hline
\end{tabular}

Fonte: União Européia: Eurobarometer 37, 1992. América Latina: Latinobarômetro, 1996, dados para Argentina, Bolívia, Brasil, Colômbia, Chile, Equador, México, Peru e Venezuela.

A abordagem contingente cumpre as exigências da hipótese de Churchill, tendo em vista que pede uma comparação direta entre dois regimes e que no Mediterrâneo e na América Latina, as pessoas tiveram, em geral, experiências com alternativas democráticas e autoritárias. Uma vez que a maioria esmagadora apóia a democracia sem qualificações, a interpretação é simples. Porém, não há motivos para esperar a mesma distribuição de respostas nos países pós-comunistas, pois a tríplice transformação de instituições sociais, econômicas e políticas revela provavelmente mais indícios de deficiências - e as respostas à pesquisa nos países mediterrâneos foram dadas décadas depois da re-implantação da democracia nessas nações. Ademais, quando regimes democráticos e não-democráticos são considerados preferíveis ou parecidos conforme a circunstância, as respostas não podem ser interpretadas sem que se saiba quais condições são mais importantes. Além disso, não está em oferta um regime híbrido que ofereça o que é percebido como o melhor das alternativas democrática e autoritária. Dentro de uma 
democracia estabelecida, pode fazer sentido avaliar o apoio a instituições específicas de um regime, uma vez que as partes podem ser reformadas sem alterar o todo (cf. Hibbing e Theiss-More, 1995). Porém, quando há competição entre regimes democráticos e não-democráticos, tanto governantes como governados precisam escolher entre um ou outro - com todas as suas falhas incluídas no pacote.

\section{A comparação de alternativas reais}

A abordagem idealista é impulsionada pela demanda: ela pergunta às pessoas sobre como seu país deveria ser governado, em vez de como é governado. Ao contrário, a abordagem realista reflete o lado da oferta: ela está preocupada com a maneira como as pessoas reagem aos regimes que conheceram. Isso é plenamente consistente com a história da Europa central e oriental, onde os dirigentes nacionais ou estrangeiros, em vez de os governados, decidiram como o país deveria ser dirigido e, com mais freqüência, escolheram alternativas nãodemocráticas.

Perguntando sobre democracia na prática. Para testar a hipótese Churchill, é necessário ter uma medida que obedeça a quatro critérios. Primeiro, ela deve referir-se a regimes políticos reais, em vez de a ideais ou símbolos políticos abstratos. Em segundo lugar, deve ser holística, isto é, convidar a um julgamento sobre o regime como um todo, com todos os seus problemas, pois o fato de alguém não gostar de alguns aspectos de um regime pode refletir um desejo de reforma, em vez de uma rejeição da democracia. Em terceiro lugar, uma vez que a democratização tem a ver com a competição com alternativas autoritárias, deve-se fazer comparações entre regimes. Tendo em vista que a democracia pode ser preferida como o mal menor, uma quarta exigência é que a medida comparativa deva registrar graus de sentimento tanto negativo quanto positivo. A seqüência das questões sobre regime do New Democracies Barometer é projetada para cumprir todos esses critérios.

$P$. Eis uma escala para classificar como o governo funciona. O topo, +100 , é o melhor; a base, -100, é o pior. Onde você poria:

a) $O$ antigo regime comunista?

b) Nosso atual sistema de governo, com eleições livres e muitos partidos?

As questões estão ancoradas institucionalmente: são sobre um sistema de governo e não sobre idéias e símbolos abstratos. Cada questão exige uma classificação do regime como um todo, pois os cidadãos não podem escolher e misturar elementos de diferentes regimes, mas devem encarar o regime tal como é: um pacote produzido pela negociação entre as elites. Tal como todos os pactos, o resultado é uma conciliação entre as deficiências e a necessidade de melhora. Assumir uma posição em relação ao regime é como tomar posição numa pergunta 
de referendo que foi formulada pelas elites: os cidadãos comuns só podem votar sim ou não, ou se abster.

As questões referem-se a regimes históricos e não a ideais ou símbolos. Pede-se aos indivíduos que avaliem o regime comunista tal como eles o conheceram por experiência pessoal, em vez de julgar o comunismo tal como se supunha que viria a ser no futuro utópico. O atual sistema de governo não é descrito como uma democracia, devido a sua carga simbólica, e num país como a Belarus, na época do trabalho de campo, havia motivos para questionar o caráter democrático do regime. A pergunta sobre o atual regime formulada imediatamente após o regime comunista ajuda a concentrar o foco no sistema, distinto do governo do momento. Para reforçar esse ponto, o sistema atual é descrito corretamente como tendo eleições livres e muitos partidos, características nem sempre vistas com favor por aqueles para os quais a pletora de partidos e a competição eleitoral são sinais de confusão e conflito.

As pessoas na Europa central e oriental estão muito melhor qualificadas para fazer um julgamento comparativo sobre a democracia do que os europeus ocidentais ou anglo-americanos, pois podem fazê-lo partir da experiência pessoal direta. O uso da comparação evita o limbo do subjetivismo na questão sobre satisfação com a democracia, que não compara uma democracia existente com alternativas potenciais. Perguntar ao respondente médio o que ele ou ela deduz do presente, ao mesmo tempo em que se ignora o passado, é não compreender a maneira como a socialização em um regime comunista leva as pessoas a avaliar uma nova democracia à luz de uma vida inteira sob um regime não-democrático. A seqüência das questões enfatiza a comparação, pois o ponto de partida é a avaliação de um regime que o respondente conheceu durante quase toda a sua vida.

O fato de se oferecerem classificações tanto negativas como positivas segue a lógica do "mal menor" da hipótese de Churchill: um regime que é ruim pode ser preferível se a alternativa a ele é terrível. Enquanto a teoria da poliarquia de Dahl identifica somente o melhor e o segundo melhor, essa escala pode acomodar toda a gama de regimes, do melhor ou segundo melhor, ao segundo pior ou o absolutamente pior. A distância entre um regime classificado como "-100" e outro com "-50" é tão grande quanto a diferença entre uma poliarquia classificada como "+50" e uma democracia como "+100". Na medida em que a insatisfação com o regime comunista se aproxima de "-100", quase qualquer outro regime será preferível. Em vez de elaborar um modelo da democratização como um processo de avanço na direção de um ideal inatingível, nos regimes pós-comunistas, podemos estabelecê-la como a fuga da insatisfação absoluta (Rose, 1992).

O foco nas diferenças entre regimes deixa intencionalmente muita coisa em aberto, como, por exemplo, se o regime comunista estava mais perto de suas 
origens totalitárias ou introduzira uma liberalização substancial em sua fase póstotalitária. Deixa abertas também questões institucionais como se o regime é um sistema parlamentarista ou presidencialista, pois ambos são consistentes com a democracia. Não se fazem pressuposições sobre se o novo regime adota uma forma determinada de sistema econômico: isso é objeto de questões paralelas, mas separadas. A questão final sobre o regime é muito aberta. Ela pede que o entrevistado avalie: c) Nosso sistema de governo dentro de cinco anos. A questão reconhece a importância política das expectativas futuras, tanto quanto dos julgamentos retrospectivos. A questão não é idealista ao perguntar às pessoas se esperam que a democracia se complete em um futuro previsível. Também não pergunta sobre a satisfação com o modo como a democracia está se desenvolvendo. É uma medida de esperanças ou de medos em relação ao que ainda não se sabe.

Divisões intra e entre países. Quando se pede uma avaliação do antigo regime comunista, em todos os países a população se divide. Nos nove países do New Democracies Barometer, uma média de $46 \%$ dá ao velho regime uma classificação positiva e 44\%, negativa. O respondente médio está indeciso, colocando o regime em zero, numa escala que vai do "céu" (+100) ao "inferno" (-100). Uma vez que os resultados vêm de um único survey, se poderia argumentar que, nos regimes póscomunistas, as pessoas costumam "reescrever" suas visões do passado. Na verdade, isso não acontece. Os surveys do NDB de 1991 até 1995 mostram muito pouca alteração na porcentagem agregada dos que endossam o velho regime. A dura experiência de vida em um regime comunista deixou marcas indeléveis na mente das pessoas (Rose e Haerpfer, 1996, figura 2.1). Isso também transparece pelo fato de que mais pessoas vêem mais o antigo regime como inferno absoluto do que como céu absoluto. Na República Tcheca, 23\% classificaram os comunistas em "-100"; na Romênia, 22\% fizeram o mesmo com o regime de Ceausescu, enquanto um por cento deu ao velho regime a classificação mais positiva. No conjunto dos países do NDB, $12 \%$ deram ao antigo regime a pior classificação possível, em comparação com cinco por cento que Ihe deram a melhor nota.

Há diferenças substanciais entre países quanto ao modo como as pessoas avaliam o velho regime. A classificação mais alta obtida por ele foi na Belarus, onde dois terços foram positivos, e na Ucrânia, onde $55 \%$ foram positivos. 0 apoio ao antigo regime nesses países combina sentimentos em relação à era comunista e ao Estado soviético, que estão inextricavelmente ligados. A divisão da Tchecoslováquia também deve ter afetado de modo semelhante a avaliação que os eslovacos fazem do antigo regime. A classificação altamente positiva na Hungria parece ser influenciada pelas condições relativamente liberais existentes sob um regime que colaborava com Moscou, mas minimizava a repressão de seu próprio povo. Em três países onde a repressão continuou até o fim da era comunista - República Tcheca, 
Romênia e Polônia - a maioria absoluta deu uma nota negativa ao regime comunista.

Quando questionadas sobre e regime atual, as sociedades permanecem divididas, mas em proporções diferentes. Nos nove países do NDB, $53 \%$ são positivos, $12 \%$ indecisos e 35\%, negativos (Figura 2). Na República Tcheca, há um grande consenso em favor do novo regime: $78 \%$ são positivos, mais do que o triplo da proporção a favor do antigo regime. Na Polônia, mais de dois terços também são positivos. A Belarus e a Ucrânia são os únicos países onde relativamente poucos são positivos; nos dois casos estão avaliando um regime novato identificado com o colapso da União Soviética. Na Hungria, uma maioria é positiva em relação ao novo regime, mas ainda assim, ela é menor do que aqueles que se manifestam positivamente sobre o antigo regime.

\section{FIGURA 2}

Avaliação de regimes - passado, presente e futuro

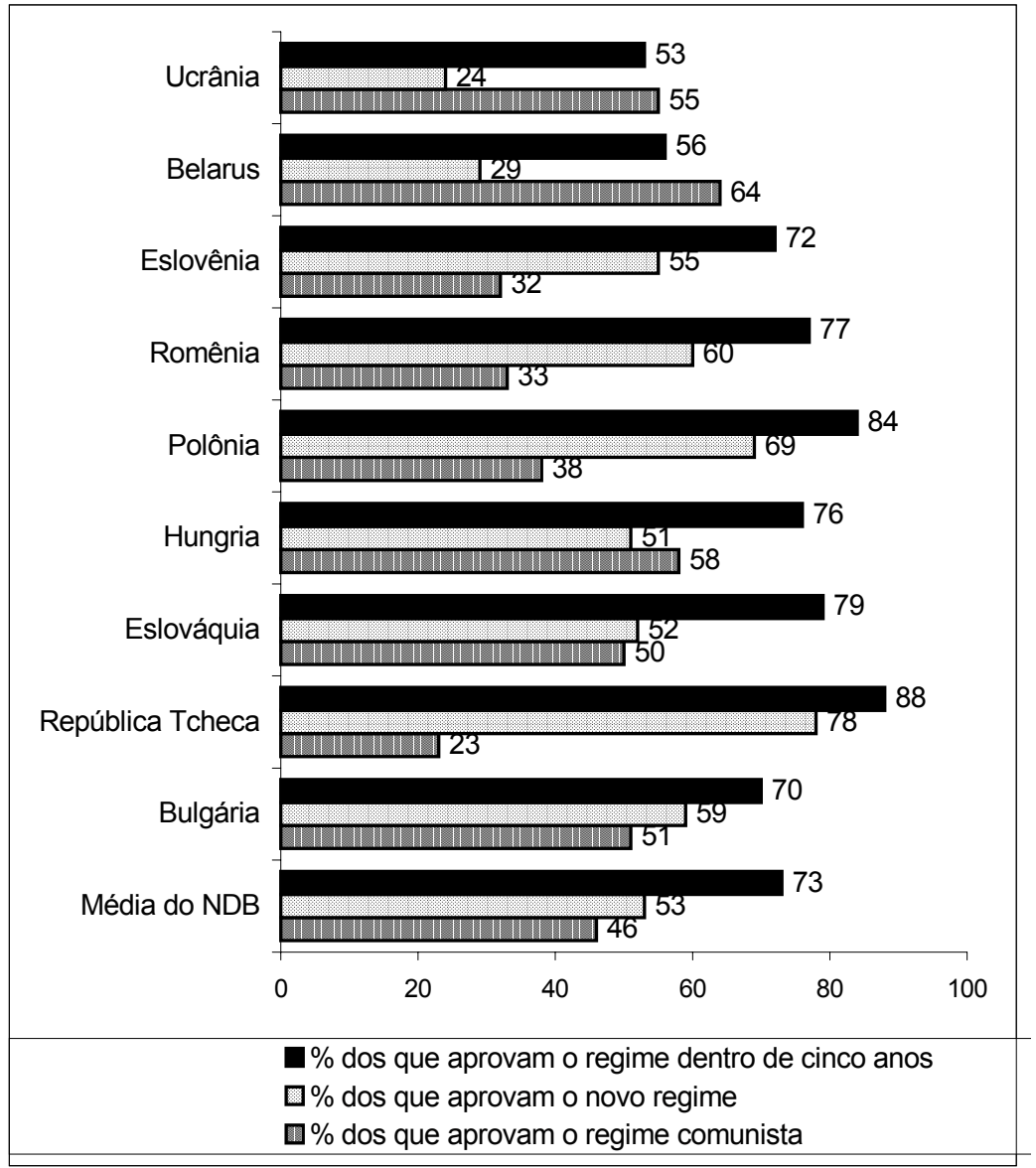

Fonte: Paul Lazarsfeld Society, New Democracies Barometer III 
Em termos dinâmicos, a questão crítica é a direção em que as atitudes individuais estão se movendo. Uma maneira de medir isso é entrevistar ano após ano um painel dos mesmos respondentes. Em 1991, quando foi lançado o New Democracies Barometer, o acompanhamento da opinião de indivíduos com novas entrevistas anuais foi rejeitado. Para fazer isso, seria necessário manter um registro em cada país do nome, do endereço e da opinião política de cada respondente, um risco grande demais, tendo em vista a história passada das sociedades do centro e do leste europeu. Para avaliar como as condições políticas estão mudando, o survey do NDB pede às pessoas para classificar o regime tal como elas esperam que ele seja dentro de cinco anos.

As esperanças superam de longe os temores: $73 \%$ fazem uma avaliação positiva para o regime no futuro, 20 pontos percentuais a mais dos que aprovam o regime atual e 27 pontos a mais dos que aprovam o antigo regime comunista. Até mesmo na Belarus e na Ucrânia, uma maioria tem expectativas positivas. Além disso, a grande maioria parece razoavelmente confiante quanto ao que o futuro trará, pois apenas $14 \%$ respondem que não sabem ou dão uma nota zero. Porém, o survey do NDB deixa a direção da mudança em aberto. As pessoas desses países podem esperar que seu regime venha a ser uma democracia saudável em cinco anos, ou alguns podem esperar a continuação da democratização, enquanto outros esperam um crescimento em apoio para alguma alternativa não-democrática. Tendo em vista as avaliações diversas dos regimes do passado e do presente, devemos perguntar: que tipo de regime, democrático ou não-democrático, as pessoas esperam que seu país tenha no futuro?

\section{Apoio a alternativas não-democráticas}

Uma busca por tentativa e erro de uma alternativa ao comunismo não se dirige necessariamente para a democracia. Por definição, um regime pós-comunista só pode ser novato, e cinco dos países cobertos pelo New Democracies Barometer são também Estados novos. Essas experiências fazem com que cada cidadão tenha consciência de que são possíveis formas alternativas de governo. Contudo, a insatisfação com o regime atual não é em si mesma uma prova do apoio a uma alternativa autoritária. As páginas anteriores documentaram que embora somente metade dos cidadãos dos países da União Européia esteja satisfeita com a democracia, uma grande maioria quer uma democracia reformada e "melhor", em vez de uma alternativa não-democrática. Os países pós-comunistas ainda precisam mostrar o compromisso de longo prazo com a democracia existente nas democracias estabelecidas da Europa ocidental. 


\section{Baixo endosso de massa para alternativas não-democráticas}

Para testar em que medida os novos regimes são vulneráveis ao colapso, o New Democracies Barometer perguntou primeiramente às pessoas se achavam que havia uma possibilidade de fechamento do Parlamento e dos partidos políticos, acontecimento para o qual havia muitos precedentes históricos na Europa central e oriental. O respondente médio julgou que isso não era muito provável, e $21 \%$ disseram que não era provável de forma alguma. Mas 31\% achavam que isso poderia acontecer e seis por cento, que era muito provável que ocorresse.

Quando se pergunta se as pessoas apoiariam a suspensão do Parlamento e dos partidos, $74 \%$ dizem que não (Figura 3). Ademais, os que desaprovam fortemente a derrubada do novo regime superam os que são fortemente a favor por uma margem de cinco para um. A insatisfação com o novo regime é consistente com a preferência pela reforma de suas instituições, em vez de dispensá-las. Quase a metade dos insatisfeitos com a nova democracia é contra a suspensão do Parlamento e a abolição dos partidos. Embora existam diferenças entre países no apoio ao novo regime, até mesmo na Ucrânia, onde as atitudes negativas são mais fortes, menos da metade gostaria ativamente de se ver livre das instituições democráticas. Uma maioria de $52 \%$ dos respondentes do NDB é de democratas confiantes, contra a suspensão do Parlamento, possibilidade que julgam muito improvável ou totalmente improvável. Além disso, um quinto são democratas ansiosos, contrários a acabar com as instituições democráticas, mas preocupados com que isso possa acontecer. Os autoritários esperançosos, os que são contra as instituições representativas e acreditam que elas podem ser derrubadas, compõem também um quinto das respostas, aumentadas por alguns poucos antidemocratas pessimistas, que gostariam de se livrar do Parlamento, mas não esperam que isso ocorra.

\section{FIGURA 3}

\section{Apoio limitado à abolição do Parlamento e dos partidos}

$P$. Algumas pessoas acham que este país seria mais bem governado se o Parlamento fosse suspenso e não tivéssemos tantos partidos políticos. Se o Parlamento fosse suspenso e os partidos abolidos, você aprovaria ou desaprovaria?

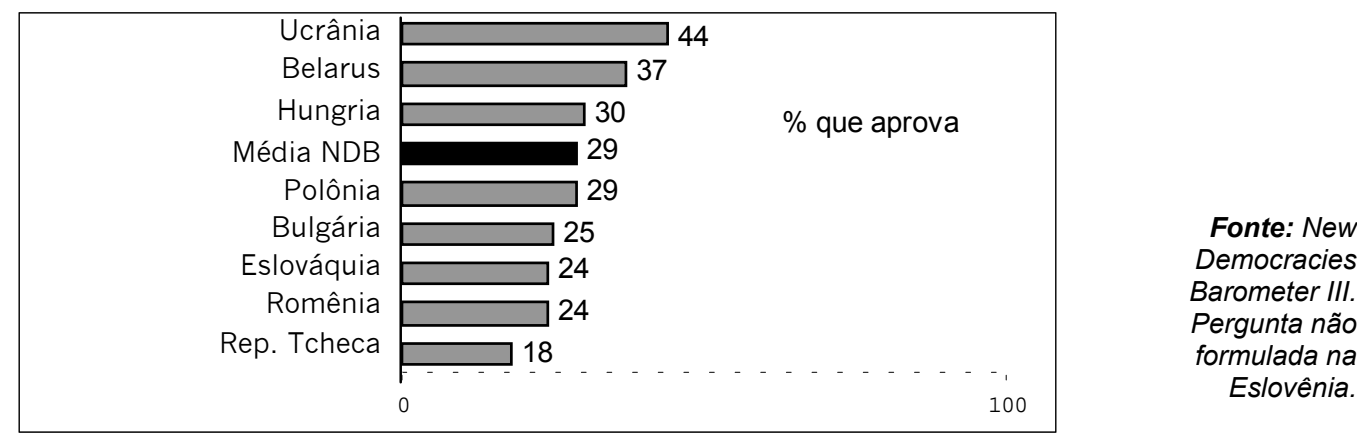


Uma vez que as pessoas que se opõem à democracia podem discordar sobre qual alternativa seria melhor, o New Democracies Barometer pergunta também se as pessoas são um pouco ou muito favoráveis a várias hipóteses de regime (Tabela 3). Para aqueles insatisfeitos com a democracia, uma volta ao comunismo é uma alternativa familiar. Porém, menos de um em cinco apóiam a volta ao passado comunista. A rejeição é geralmente intensa; $56 \%$ se opõem muito ao retorno do velho regime, em comparação com os cinco por cento que são fortemente favoráveis a fazer o relógio andar para trás. Há diferenças substanciais entre países; na República Tcheca, somente sete por cento dizem que gostariam da volta do comunismo, enquanto que na Belarus, 34\% escolhem essa alternativa. Uma característica notável das respostas é que o endosso do retorno ao comunismo é menos da metade da proporção que expressa uma avaliação positiva desse regime (cf. Figura 2 e Tabela 3).

A nostalgia do passado não conduz usualmente a um desejo de voltar ao passado. Isso é bom, pois as instituições que sustentavam o velho regime, tais como a União Soviética, o Pacto de Varsóvia e o Comecon, não existem mais. Embora muitos políticos da era comunista continuem ativos, eles estão espalhados por vários partidos, e os sucessores dos antigos partidos governantes tenderam a ganhar mais votos onde reagiram às mudanças geopolíticas fazendo do "ex" a parte principal do termo ex-comunista (cf. Kitschelt, 1995; Ishiyama, 1997).

O governo militar é uma forma familiar de regime não-democrático. A América Latina, o Oriente Médio e a África oferecem muitos exemplos da tomada do poder por um "homem a cavalo". No passado, figuras militares foram importantes na Europa central e oriental, como por exemplo, o marechal Pilsudski, na Polônia, e o almirante Horthy, na Hungria. Porém, um golpe militar requer que a alta hierarquia militar veja seu papel como o de garantir a ordem e o bom governo de um país, ou oficiais jovens que dêem um golpe de "coronéis" (cf. Stepan, 1986). Nos regimes comunistas, os militares estavam sujeitos a um alto grau de controle político; eles evitavam a política interna e se concentravam na preparação para a Terceira Guerra Mundial. A visão de que os militares devem ficar fora da política é compartilhada pela população. Somente dez por cento apóiam a tomada do poder por eles; em nenhum país, mais do que quinto é a favor de um regime militar. Isso é particularmente notável, pois uma proporção muito maior de cidadãos confia mais (ou pelo menos desconfia menos) na instituição Exército do que no Parlamento ou nos partidos políticos. Porém, mesmo entre a minoria que confia no exército, menos de um quarto receberia bem sua tomada do poder. 


\section{TABELA 3}

\section{Quais são as alternativas à democracia?}

$P$. Nosso sistema atual de governo não é o único que este país já teve. Algumas pessoas dizem que estaríamos em situação melhor se o país fosse governado de forma diferente. O que você pensa?

a) Devemos retornar ao regime comunista

b) O exército deveria governar o país

c) É melhor acabar com o Parlamento e as eleições e ter um líder forte que possa decidir rapidamente as coisas

d) Um retorno à monarquia seria melhor

e) As decisões mais importantes sobre a economia deveriam ser tomadas por especialistas e não pelo governo e o Parlamento

\begin{tabular}{|l|r|r|r|r|r|}
\cline { 2 - 6 } \multicolumn{1}{c|}{} & \multicolumn{1}{c|}{ a } & \multicolumn{1}{c|}{$c$} & \multicolumn{1}{c|}{$d$} & \multicolumn{1}{c|}{ c } \\
\hline Média NDB & $18 \%$ & $10 \%$ & $32 \%$ & $8 \%$ & $72 \%$ \\
\hline Bulgária & 35 & 15 & 45 & 19 & 66 \\
\hline Rep. Tcheca & 7 & 2 & 16 & 3 & 80 \\
\hline Eslováquia & 16 & 4 & 24 & 1 & 89 \\
\hline Hungria & 18 & 2 & 18 & 5 & 83 \\
\hline Polônia & 18 & 11 & 35 & 7 & 60 \\
\hline Romênia & 12 & 18 & 31 & 17 & 56 \\
\hline Eslovênia & 12 & 8 & 41 & não perg. & 63 \\
\hline Belarus & 34 & 15 & 44 & 8 & 69 \\
\hline Ucrânia & 25 & 11 & 45 & 7 & 78 \\
\hline
\end{tabular}

Fonte: Paul Lazarsfeld Society, Viena, New Democracies Barometer III. A porcentagem positiva é a soma dos que concordam muito e um pouco.

Os regimes dominados por um líder forte foram comuns na Europa central e oriental. Kenneth Jowitt (1992) sustenta que décadas de exposição ao domínio leninista reforçaram a aceitação da liderança autoritária. No entanto, o desejo por liderança efetiva não é necessariamente não-democrático: ele está presente em todas as eleições presidenciais americanas e também nas democracias européias bem estabelecidas (cf. Rose e Mishler, 1996). Para testar o grau dessa demanda, o New Democracies Barometer perguntou às pessoas se elas gostariam de um líder forte governando sem Parlamento e eleições. Um pouco mais de um terço respondeu positivamente. Em países onde a liderança forte foi especialmente evidente, como a Romênia sob Nicolae Ceausescu, e a Eslováquia, onde Vladimir Meciar conduziu o país à independência e depois entrou em conflito com o presidente e o Parlamento, o apoio a um líder forte fica abaixo da média. Ainda que os jornalistas dêem crédito a líderes políticos com personalidades fortes, é mais provável que os líderes autoritários "desmagnetizem" os cidadãos: 37\% rejeitam fortemente a idéia de um líder no lugar do Parlamento e somente 15\% apóiam muito essa alternativa não-democrática. 
A monarquia tem uma ressonância histórica positiva somente em dois países pesquisados, Bulgária e Romênia, onde foi um símbolo nacional, embora politicamente divisor, de autoridade no período entre guerras e durante a Segunda Guerra Mundial. Na Bulgária, onde se estabeleceu o regime monárquico no processo de luta pela independência do Império Otomano, 19\% a endossam e, na Romênia, $18 \%$. Em outros países, a independência nacional foi conquistada em revoltas contra um monarca imperial e o republicanismo é dado como certo; em média, apenas cinco por cento apóiam a monarquia. Uma vez que esse regime pode ser constitucional, seu endosso não é uma ameaça à democracia; na Espanha, o rei foi associado positivamente à democratização (cf. Linz e Stepan, 1996, 89 ss.; Rose, 1995).

Transformar a economia dirigida em algum tipo de economia de mercado é um problema sério em todos os países pós-comunistas. Para tanto, é preciso capacidade técnica, bem como a autoridade de uma eleição popular. Às vezes, chega-se a dizer que as eleições livres são um obstáculo à execução do que é necessário do ponto de vista técnico para promover o crescimento econômico, e as políticas seriam melhores se feitas por tecnocratas econômicos "motivados para perseguir os objetivos postulados pela análise econômica normativa tradicional" (Williamson, 1994, 13). Em todos os países, uma grande maioria concorda com isso. A amplitude do apoio popular aos especialistas que tomam as decisões econômicas sugere que não há tanto conflito entre ideologias econômicas concorrentes quanto existe um abismo entre as políticas que funcionam e as que não funcionam (cf. Duch, 1993).

\section{Identificando uma síndrome autoritária}

A oposição à democracia pode vir de muitas direções diferentes. Mesmo que a maioria não goste do novo regime, pode haver discordâncias sobre o que gostariam de pôr em seu lugar: alguns são a favor de um homem forte, enquanto outros se opõem a ditadores, mas querem economistas tecnocratas para tomar as decisões econômicas. Na falta de acordo sobre uma alternativa, as instituições democráticas poderiam permanecer indefinidamente em funcionamento.

A análise fatorial oferece um método estatístico direto para determinar se as opiniões sobre as seis alternativas à democracia examinadas acima refletem uma preferência geral por um regime não-democrático. Os resultados mostram que a aprovação de um retorno ao comunismo, da dissolução do Parlamento e dos partidos, da ditadura e do golpe militar constituem uma única dimensão de apoio a alternativas não-democráticas (Tabela 4). Juntas, essas quatro atitudes respondem por $32 \%$ da variância total na análise. Igualmente significante, o amplo apoio à tomada de decisões pelos especialistas em economia não é o desejo de que um "PhD a cavalo" tome o poder: trata-se de uma demanda por ação efetiva de profissionais. Ela constitui um segundo fator, sem relação com o endosso de 
alternativas não-democráticas. Isso é consistente com o argumento de Dahl (1971) de que a tomada de decisões por especialistas não é inconsistente com a democracia e, em alguns casos, é até necessária. A monarquia também é um fator separado, não associado ao apoio a regimes autoritários. Isso não surpreende, pois na grande maioria dos países pós-comunistas, uma monarquia é simplesmente irrelevante.

TABELA 4

Análise fatorial de regimes alternativos

\begin{tabular}{|l|c|c|c|c|}
\cline { 2 - 3 } \multicolumn{1}{c|}{} & \multicolumn{1}{c|}{ Fator 1 } & Fator 2 & \multirow{2}{*}{ Fator 3 } & \multirow{2}{*}{ Comunalidade } \\
\hline Alternativas & \multicolumn{2}{c|}{ Rotação ortogonal varimax } & & 60 \\
\hline Regime comunista & 73 & -10 & -16 & 62 \\
\hline Líder forte & 71 & 31 & 14 & 54 \\
\hline Governo militar & 66 & -13 & -26 & 46 \\
\hline $\begin{array}{l}\text { Suspensão de } \\
\text { Parlamento e partidos }\end{array}$ & 62 & 28 & 02 & 86 \\
\hline $\begin{array}{l}\text { Especialistas dirigem a } \\
\text { economia }\end{array}$ & 03 & 92 & -01 & 93 \\
\hline Monarquia & 05 & 00 & 97 & \\
\hline Eigenvalue & 1.96 & 1.04 & 1.00 & 66.7 \\
\hline Variância explicada & 32.6 & 17.5 & 16.6 & \\
\hline
\end{tabular}

Fonte: Paul Lazarsfeld Society, Viena, New Democracies Barometer III. Uma vez que não foi formulada na Eslovênia, a questão sobre a monarquia foi excluída da análise fatorial; número total de respondentes: 7.733.

As respostas a quatro questões sobre a suspensão do Parlamento, governo de um líder forte, controle pelo exército ou uma volta ao comunismo podem ser combinadas numa única escala de rejeição de alternativas não-democráticas. Essa escala mede um conjunto diferente de preferências políticas do que as escalas de três regimes; a correlação entre ela e a aprovação positiva do regime atual é insignificante. Isso é também ilustrado pelo fato de que os húngaros, não obstante ocuparem o terceiro lugar entre os que menos apóiam o regime atual, estão em segundo lugar na rejeição de alternativas não-democráticas.

Embora haja algum apoio para cada alternativa autoritária, a distribuição total se inclina para a ponta mais baixa (Figura 4). Quase a metade rejeita todas as quatro alternativas não-democráticas; um quarto rejeita todas, exceto uma. Um sexto está dividido, apoiando duas alternativas democráticas e duas autoritárias. menos de um em dez endossa três ou quatro regimes não-democráticos. 


\section{FIGURA 4}

\section{Apoio limitado a alternativas não-democráticas}

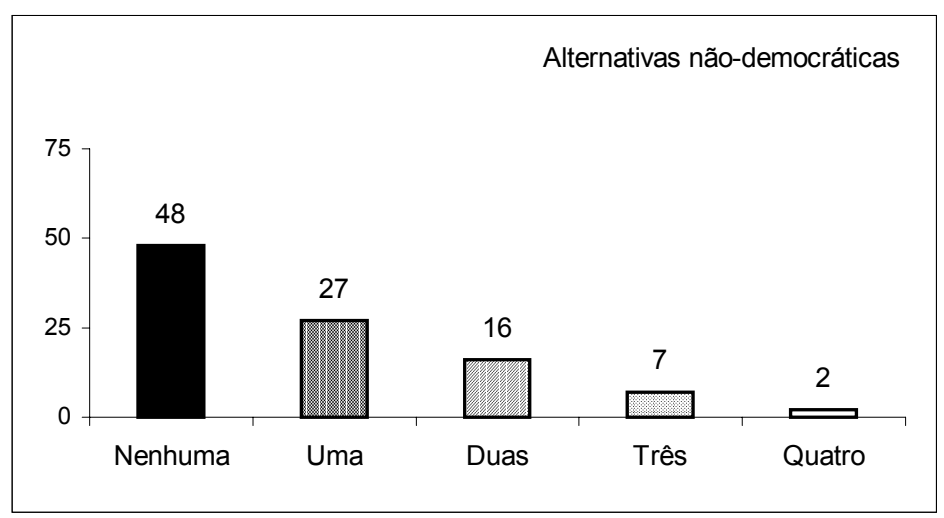

Fonte: Paul Lazarsfeld Society, New Democracies Barometer III.

\section{Explicando a variação e não a uniformidade}

Os historiadores que estudam um único país da Europa central ou oriental tendem a enfatizar os aspectos uniformes desse país, tais como a língua ou a religião. Assim como um historiador americano pode explicar a história dos Estados Unidos em termos de fatores americanos, do mesmo modo os búlgaros ou húngaros podem citar a história de seus países para explicar o que acontece lá. Os políticos que fundam nações e que buscam justificar a criação de novos Estados a partir da ruptura de Estados multinacionais são especialmente fervorosos na ênfase das preocupações coletivas com a identidade, a língua ou a cultura, que se presume que são muito valorizadas por todos que pertencem ao Volk. Ao mesmo tempo em que reprimiam amiúde os ideais nacionalistas, os regimes comunistas proclamavam que todos deveriam concordar sobre a correção dos princípios marxistas-leninistas tais como proclamados pelo Estado-partido.

Muitas teorias sobre as sociedades pós-comunistas implicam uma uniformidade de resposta: espera-se que todos que vivem numa determinada sociedade avaliem o governo mais ou menos da mesma forma. A escala céu-inferno proporciona um teste empírico desse pressuposto, pois não se pergunta às pessoas somente se elas aprovam ou desaprovam o regime, mas também que registrem o grau em que são positivas ou negativas.

Com consistência, os surveys do NDB indicam que os indivíduos se dispersam amplamente ao longo de uma escala de 201 pontos que mede a aprovação ou desaprovação de um regime. A questão é facilmente negligenciada quando, para simplificar a apresentação, se fica nas porcentagens dos que aprovam o regime, pois a aprovação pode variar de um fraco +1 a um vibrante +100 . A nota média dada ao regime atual, +5 , disfarça uma grande variação de atitudes entre 
indivíduos na escala céu-inferno, como ilustra a Figura 5.

No interior de cada nova democracia há substanciais diferenças de opinião na classificação que os indivíduos dão ao novo regime. Qualquer que seja a média nacional, o desvio padrão em torno da média é grande. As respectivas médias nacionais (desvios-padrões) são: Bulgária 14 (51); República Tcheca 33 (39); Eslováquia 5 (46); Hungria 1 (50); Polônia 18 (41); Romênia 12 (52); Eslovênia 9 (48); Belarus -21 (49); e Ucrânia -21 (49). Além disso, encontra-se um alto grau de variação em apoio ou rejeição do novo regime em cada survey NDB, e também em outras medidas de democracia (ver por ex., Rose e Haerpfer, 1996; Simon, 1996). A amplitude da variação rejeita as teorias "nacionalistas" que supõem que todos as pessoas de um país irão reagir da mesma forma à experiência comum da substituição de regimes. As teorias da cultura política não podem ser invocadas para explicar o apoio à democracia, na medida em que enfatizam valores compartilhados dentro de uma cultura ou numa área cultural ampla (cf. Huntington, 1996). Na ausência de uniformidade nas avaliações do regime atual, uma interpretação cultural das medidas acima poderia prever uma instabilidade crônica ou o colapso dos regimes democráticos devido à falta de consenso cultural.

\section{FIGURA 5}

Variações no apoio ao regime atual

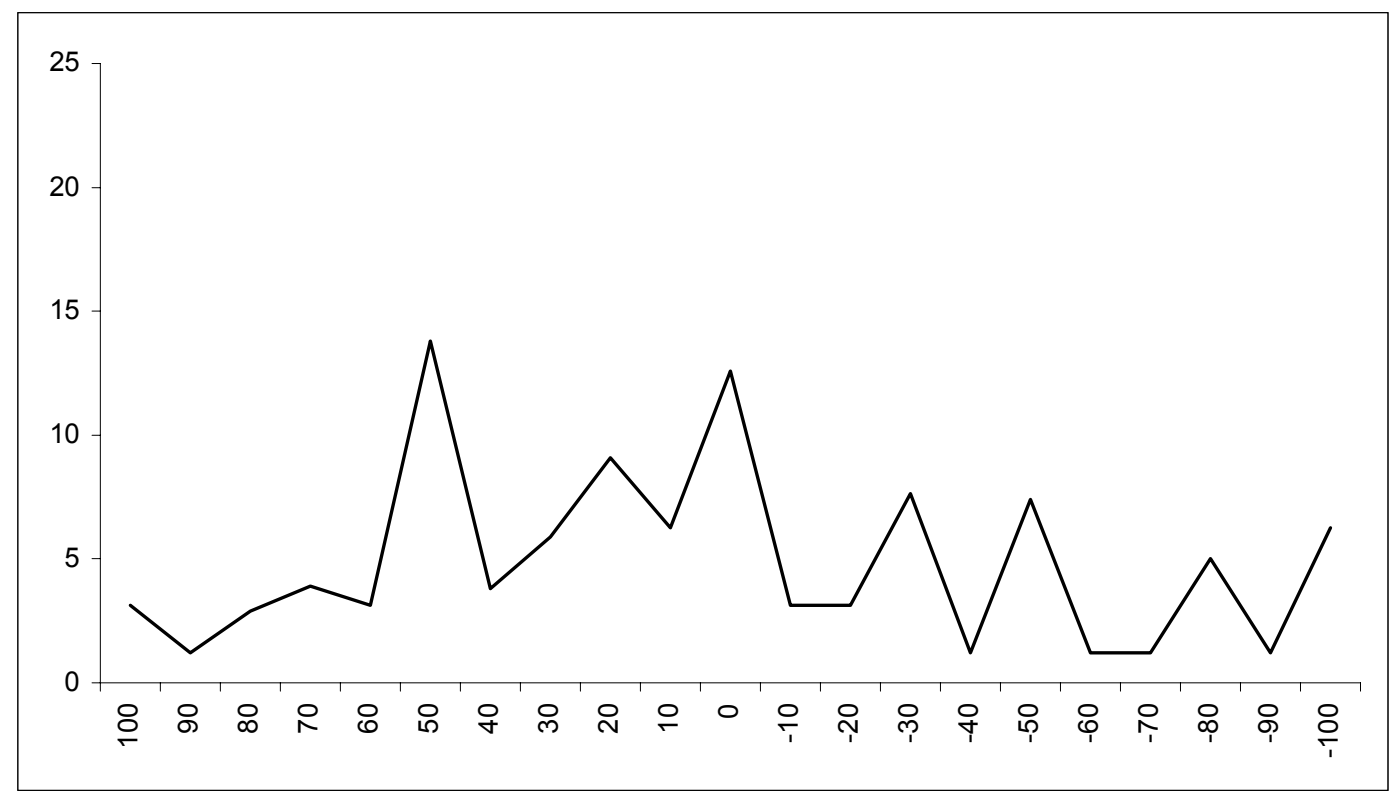

Fonte: Paul Lazarsfeld Society, New Democracies Barometer III.

Na literatura das ciências sociais, várias teorias procuram explicar porque as pessoas diferem quanto aos valores políticos; em geral, essas teorias são 
desenvolvidas e testadas em democracias estabelecidas, em especial, nas mais antigas e, de algum modo, a democracia estabelecida mais característica, os Estados Unidos. Dois pontos de vista teóricos disputam a primazia na explicação de porque as pessoas apóiam ou rejeitam o governo democrático. As teorias culturais enfatizam valores e crenças políticas fundamentais, formadas durante um longo processo de socialização política iniciado na infância (ver, por ex., Almond e Verba, 1963; Inglehart, 1990). Embora assumam diversas formas, as teorias da socialização concordam que o apoio político é adquirido cedo na vida, em conseqüência de experiências que refletem a influência dos pais sobre a etnicidade e a prática religiosa do indivíduo, e educação, geração, gênero e classe social. Cada passo na socialização diferencia os indivíduos uns dos outros; o objeto da pesquisa empírica é identificar quais passos em particular são mais importantes para o apoio às alternativas democrática e autoritária.

Ao contrário, as teorias da escolha racional enfatizam que o apoio ao regime depende substancialmente do desempenho político (ver, por ex., Weatherford, 1992; Przeworski, 1991). Um grupo de teorias enfatiza a capacidade do regime de obter um bom desempenho da economia, e as decisões que os governantes tomam sobre como os benefícios econômicos serão distribuídos. A hipótese básica é que os indivíduos apoiarão um governo (e, por extensão, um regime democrático) se acreditarem que "vale a pena" para eles fazer isso. Uma vez que os indivíduos diferem em condições e expectativas econômicas, o objeto da pesquisa empírica é identificar quais as condições econômicas que têm maior influência, positiva ou negativa, no apoio às alternativas democrática e autoritária. Um segundo conjunto de teorias sublinha o desempenho político. Os indivíduos ficam satisfeitos com a democracia quando ela funciona bem, de modo justo, e oferece liderança popular; ocorre insatisfação quando ela funciona mal, exibindo, por exemplo, corrupção ou ilegalidades do tipo Watergate. Numa democracia estabelecida, é fácil realizar surveys que medem o que as pessoas pensam sobre o funcionamento do governo, mas dificilmente faz sentido perguntar sobre alternativas não-democráticas.

Embora os pontos de vista da socialização e do desempenho sejam defendidos com tenacidade, a distinção teórica entre eles é exagerada (cf Finifter \& Mickiewicz, 1992; Miller, Hesli \& Reisinger, 1994 e 1997). Ambas as abordagens concebem o apoio como um produto da experiência. Elas se diferenciam principalmente em enquadramentos de tempo e nas experiências consideradas mais relevantes. As teorias da socialização enfatizam a primazia das experiências nos primeiros anos de vida, que perdurariam na vida adulta. As teorias do desempenho enfatizam as experiências recentes e contemporâneas que são freqüentemente vistas como cambiantes (por ex., o estado da economia), ou mesmo efêmeras (a popularidade de determinados políticos). Porém, até mesmo essa distinção é exagerada, pois as teorias da socialização reconhecem que embora 
comece na infância, o aprendizado político é um processo contínuo ao longo da vida; a pesquisa da socialização enfatiza cada vez mais a socialização adulta como mais importante que a infantil na formação das atitudes políticas (Conover \& Searing, 1994).

Em nossa visão, as teorias da socialização e do desempenho não são antagônicas, mas complementares. Elas podem ser integradas em um único modelo de aprendizado durante toda a vida (Rose \& McAllister, 1990), no qual o apoio ao regime é formado inicialmente pelas primeiras experiências e depois evolui continuamente ao longo da vida adulta, enquanto as crenças iniciais são reforçadas ou contestadas por experiências posteriores. Os valores e as atitudes políticas podem ser relativamente estáveis no curto prazo e determinadas inicialmente pelas experiências de formação. Porém, a longo prazo, as atitudes em relação às instituições políticas e sociais podem mudar consideravelmente em reação a experiências mais recentes e avaliações de desempenho.

A idéia inerente ao modelo de aprendizado em toda a vida segue de perto a concepção de Fiorina $(1989,89-91)$ da identificação partidária política americana como uma "contagem em marcha de avaliações retrospectivas". Expresso simbolicamente, o que estamos propondo é um modelo explicativo em que

$$
\mathrm{APOIO}_{\mathrm{p}}=\sum_{i=1}^{p} \mathrm{~B}_{\mathrm{i}} \mathrm{RE}_{\mathrm{i}}+\mathrm{u}_{\mathrm{p}} .
$$

onde $R E_{i}$ representa a avaliação retrospectiva que o indivíduo faz de um regime experimentado em qualquer período (i); $B_{i}$ representa os pesos relativos atribuídos à experiência em qualquer período; e $u_{p}$ é um termo de erro. Isso pode ser reescrito:

$$
\mathrm{APOIO}_{\mathrm{p}} \cdot \mathrm{APOIO}_{\mathrm{p} \cdot 1}+\mathrm{B}_{\mathrm{p}} \mathrm{RE}_{\mathrm{p}}+\left(\mathrm{u}_{\mathrm{p}}-\mathrm{u}_{\mathrm{p} \cdot \mathrm{1}}\right) \text {. }
$$

onde o apoio ao atual regime é um legado do apoio passado $\left(A P O O_{p-1}\right)$ tal como modificado ou atualizado por experiências ou avaliações mais recentes e contemporâneas $\left(R E_{p}\right)$. Concebidos desse modo, os modelos de socialização e desempenho são complementares.

Do ponto de vista empírico, o que está em questão é o impacto relativo de experiências variadas em diferentes pontos do ciclo de vida de um indivíduo. Numa democracia estabelecida, a diferença de APOIO em um momento $p$ e outro momento p-1 é provavelmente mínima, pois o regime permanece constante; as principais mudanças ocorrerão provavelmente nas preferências por um candidato ou um partido político, como na teoria da competição eleitoral de Schumpeter.

Nas sociedades pós-comunistas, no entanto, há uma descontinuidade fundamental decorrente do fato de que o regime que busca apoio foi transformado de um estado-partido comunista em uma democracia. Isso altera 
fundamentalmente os termos do debate sobre a importância relativa da socialização inicial em oposição ao desempenho atual, pois todo mundo é afetado pela descontinuidade dos regimes. Mas mesmo aqui as duas concepções se sobrepõem, pois é natural que os indivíduos julguem o desempenho do regime atual em comparação com lembranças do passado comunista, seja de forma negativa ou positiva (cf. Hahn, 1991). Do ponto de vista metodológico, o debate se resolve numa disputa sobre o tamanho relativo dos coeficientes para conjuntos competitivos de variáveis numa única equação regressiva.

O modelo de aprendizado durante toda a vida dá o devido reconhecimento a influências comuns a muitas sociedades, pós-comunistas ou não. Ele rejeita explicitamente a idéia de que os valores políticos básicos podem ser explicados por uma única causa e abre espaço para uma multiplicidade de influências sociais, econômicas e políticas. Para compreender a resposta em massa às transformações das sociedades pós-comunistas, devemos testar sob quais circunstâncias e em que medida as hipóteses deduzidas de teorias contrastantes explicam de fato como as pessoas comuns avaliam as alternativas de governo democráticas e nãodemocráticas (Rose, Mischler \& Haerpfer, 1998).

\section{BIBLIOGRAFIA}

ADORNO, Theodor W. et alli. (1950) The Authoritarian Personality. Nova York, Harper.

ALMOND, Gabriel A. com Roselle, Laura. (1990) Model Fitting in Communists Studies. In: ALMOND, A. Discipline Divided, Londres, Sage Publications, 66-116.

ALMOND, Gabriel A. \& Verba, Sidney. (1963) The Civic Culture. Princeton, Princeton University Press.

BARNES, Samuel H. (1967) Party Democracy: Politics in a Italian Social Federation. New Haven, Yale University Press.

(1994) Politics and Culture. In: WEIL, Frederick D. \& GAUTIER, Mary (eds.). Political Culture and Political Structure, v. 2 da série Research on Democracy and Society. Greenwich, Conn., JAI Press, 45-64.

BERGLUND, Sten \& AAREBROT, Frank. (1997) The Political History of Eastern Europe in the $20^{\text {th }}$ Century: The Struggle between Democracy and Dictatorship. Cheltenham, Edward Elgar.

BROWN, Archie, ed. (1984) Political Culture and Communist Studies. Londres, Macmillan.

CONOVER, Pamela Johnson \& SEARING, Donald D. (1994) Democracy, Citizienship and the Study of Political Socialization. In: BUDGE, Ian \& McKAY, David (eds.) Developing Democracy. Londres, Sage Publications, 24-55.

DAHL, Robert A. (1971) Polyarchy: Participation and Opposition. New Haven, Yale University Press. . (1985) A Preface to Economic Democracy. Berkeley, University of California Press.

DUCH, Raymond M. (1993) Tolerating Economic Reform: Popular Support for Transition to a Free Market in the Former Soviet Union. American Political Science Review, 87 (3): 590-608. 
ECKSTEIN, Harry. (1966) Division and Cohesion in Democracy. A Study of Norway. Princeton, Princeton University Press.

EVANS, Geoffrey \& WHITEFIELD, Stephen. (1995) The Politics and Economics of Democratic Commitment: Support for Democracy in Transition Societies. British Journal of Political Science, --, 485-513.

FINIFTER, Ada \& MICKIEWICZ, Ellen. (1992) Redefining the Political System of the USSR: Mass Support for Political Change. American Political Science Review, 86 (4): 857-864.

FUCHS, Dieter, GUIDOROSSI, Giovanna \& SVENSSON, Palle. (1995) Support for the Democratic System. In: KLINGEMANN, Hans-Dieter \& FUCHS, Diter (eds.) Citiziens and the State. Oxford, Oxford University Press, 323-353.

GIBSON, James L. (1994) The Structure of Democratic and Economic Commitments in Russia and Ukraine. Berlim, XVI World Congress of the International Political Science Association, 22-26 de agosto.

GIBSON, James L. \& DUCH, Raymond M. (1993) Support for Rights in Western Europe and the Soviet Union. Research on Democracy and Society, v. 1, JAI Press, 241-263.

GIBSON, James L., DUCH, Raymond M. \& TEDIN, Kent L. (1992) Democratic Values and the Transformation of the Soviet Union. Journal of Politics, 54 (2): 329-371.

GURR, Ted R. (1970) Why Men Rebel. Princeton, Princeton University Press.

HAHN, Jeffrey W. (1991) Continuity and Change in Russian Political Culture. British Journal of Political Science, outubro, 393-41.

HIBBING, John R. \& Theiss-Morse, Elizabeth. (1995) Congress as Public Enemy: Public Attitudes toward American Political Institutions. Nova York, Cambridge University Press.

HUNTINGTON, Samuel P. (1996) The Clash of Civilizations and the Remaking of World Order, Nova York, Simon and Schuster.

INGLEHART, Ronald. (1990) Culture Shift in Advanced Industrial Societies. Princeton, Princeton University Press.

ISHIYAMA, John. (1997) The Sickle or the Rose? Previous Regime Types and the Evolution of the Ex-Communist Parties in Post-Communist Politics. Comparative Political Studies, 30 (3): 299-330.

JOWITT, Kenneth. (1971) Revolutionary Breakthrough and National Development: The Case of Romania, 1944-1965. Berkeley, University of California Press.

KITSCHELT, Herbert. (1995) Party Systems in East Central Europe: Consolidation or Fluidity? Glasgow, University of Strachclyde Studies in Public Policy n. ${ }^{\circ} 241$.

McONTOSH, Mary \& ABELE, Dan. (1994) Conceptions of Democracy in a Changing Central and East Europe. Filadélfia, trabalho para a reunião anual da AAASS, novembro.

McINTOSH, Mary, MacIVER, Martha Abele \& ABELE, Daniel G. (1994) Publics Meet Market Democracy in Central and East Europe, 1991-1993. Slavic Review, 53 (2): 483-512.

MILLER, Arthur H., HESLI, Vicki L. \& REISINGER, William M. (1994) Reassessing Mass Support for Political and Economic Change in the Former USSR. American Political Science Review, 88 (2): 399-411.

(1997) Conceptions of Democracy among Mass and Elite in Post-Soviet Societies. British Journal of Political Science, 27 (2): 157-190.

PRZEWORSKI, Adam. (1991) Democracy and the Market: Political and Economic Reform in Eastern Europe and Latin America. Cambridge, Cambridge University Press. 
PRZEWORSKI, Adam \& TEUNE, Henry. (1970) The Logic of Comparative Social Inquiry. Nova York, John Wiley.

PUTNAM, Robert. (1993) Making Democracy Work, com Robert Leonardi e Raffaella Y. Nanetti Princeton, Princeton University Press.

ROSE, Richard. (1992) Escaping from Absolute Dissatisfaction: a Trial-and-Error Model of Change in Eastern Europe. Journal of Theoretical Politics, 4 (4): 371-93.

. (1995) Monarchy, Constitutional In: LIPSET, S. M. (ed.) The Encyclopedia of Democracy. Washington, D.C., CQ Press, v. 3, 843-847.

ROSE, Richard \& HAERPFER, Christian. (1996) Change and Stability in the New Democracies Barometer: A Trend Analysis. Glasgow, University of Strathclyde Studies in Public Policy, $n^{\circ} 270$.

ROSE, Richard \& McALLISTER, lan. (1990) The Loyalty of Voters. Londres, Sage Publications.

ROSE, Richard \& MISHLER, William. (1996a) Representation and Leadership in Post-Communist Political Systems. Journal of Communist and Transition Studies, 12, 2.

ROSE, Richard, MISHLER, William \& HAERPFER, Christian. (1998) Democracy and Its Alternatives: Understanding Post-Communist Societies. Baltimore, John Hopkins University Press.

SCHEUCH, Erwin K. (1966) Cross-National Comparisons Using Aggregate Data: Some Substantive and Methodological Problems. In: MERITT, Richard L. \& ROKKAN, Stein Rokkan (eds.) Comparing Nations. New Haven, Yale Univeristy Press, 131-168.

SIMON, Janos, (1996) Popular Concepts of Democracy in Post-Communist Europe. Glasgow, University of Strathclyde Studies in Public Policy, $n^{\circ} 273$.

SNIDERMAN, Paul M. (1993) The New Look in Public Opinion Research. In: FINIFTER, Ada W. (ed.) The State of the Discipline II. Washington D.C., American Political Science Association, 219246.

STEPAN, Alfred. (1986) Paths toward Redemocratization. In: O'DONNELL, G., SCMITTER, P. C. \& WHITEHEAD, L. (eds.) Transitions from Authoritarian Rule. Baltimore, John Hopkins University Press, 64-84.

TOKA, Gabor. (1995) Political Support in East-Central Europe. In: KLINGEMANN, Hans-Dieter \& FUCHS, Dieter (eds.) Citiziens and the State. Oxford, Oxford University Press, 354-382.

TUCKER, Robert C. (1971) The Soviet Political Mind. Nova York, W. W. Norton.

WELCH, Stephen. (1987) Issues in the Study of Political Culture: The Example of Communist Party States. British Journal of Political Science, 17, 479-500.

WILLIAMSON, John, ed. (1994) The Political Economy of Political Reform. Washington D.C., Institute for International Economics.

Traduzido do original em inglês Survey Measures of Democracy, Studies in Public Policy, no294, Centre for the study of public policy, University of Strathclyde, 1997.

Tradução e Publicação autorizadas pelo autor em março de 2002.

Tradução de Pedro Maia Soares. 